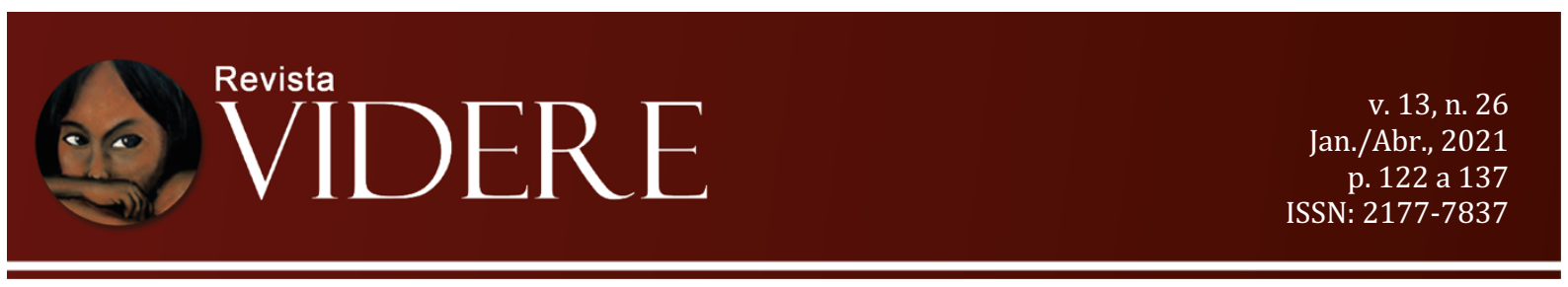

\title{
O DIÁLOGO DE DUSSEL COM MARX: DECOLONIALIDADE E MARXISMO
}

\author{
DUSSEL'S DIALOGUE WITH MARX: DECOLONIALITY AND MARXISM
}

\author{
EL DIÁLOGO DE DUSSEL CON MARX: DECOLONIALIDAD Y MARXISMO
}

\author{
Sílvia Gabriel Teixeira \\ Mestre pela FDUC e doutoranda pela FDUL \\ Universidade de Lisboa \\ silviagabriel@hotmail.com.br \\ http://orcid.org/0000-0002-4486-4105
}

José Luiz Quadros de Magalhães

Mestre e Doutor pela UFMG Pontifícia Universidade Católica de Minas Gerais jlqmagalhaes@gmail.com https://orcid.org/0000-0003-1366-7122

Resumo: Os estudos decoloniais vem com a proposta de repensar do sistema mundo moderno. Enrique Dussel ao propor a Filosofia da Libertação faz uma análise complexa sobre a América Latina, sobre o ser latino e busca, através da transmodernidade, apresentar uma ética da libertação. Contudo, para esse caminhar Dussel faz diálogos com diversos autores. No presente trabalho apresenta-se a segunda fase da filosofia dusseliana, a partir da releitura dos textos de Karl Marx, os seus encontros e pontos de divergência. A filosofia da libertação trata-se de um autodescobrimento, como um ser cidadão com direito de participação, de escolhas. A descoberta de si mesmo permite perceber o outro diverso, dentro de uma perspectiva de complementaridade.

Palavras-chave: Filosofia da libertação. Decolonialidade. Marxismo.

Abstract: Decolonial studies come with the proposal to rethink the modern world system. Enrique Dussel when proposing the Philosophy of Liberation makes a complex analysis about Latin America, about the Latin being and seeks, through transmodernity, to present an ethics of liberation. However, for this journey, Dussel dialogues with several authors. In the present work, the second phase of Dusselian philosophy is presented, based on the re-reading of Karl Marx's texts, their encounters and points of divergence. The philosophy of liberation is about self-discovery, as a citizen with the right to participate, to make choices. The discovery of oneself allows us to perceive the diverse other, within a perspective of complementarity. 
Keywords: Philosophy of liberation. Decoloniality. Marxism.

Resumen: Los estudios decoloniales vienen con la propuesta de repensar el sistema mundial moderno. Enrique Dussel al proponer la Filosofía de la Liberación hace un análisis complejo sobre América Latina, sobre el ser latino y busca, a través de la transmodernidad, presentar una ética de la liberación. Sin embargo, para este viaje,Dussel dialoga con varios autores. En el presente trabajo se presenta la segunda fase de la filosofía dusseliana, basada en la relectura de los textos de Karl Marx, sus encuentros y puntos de divergencia. La filosofía de la liberación se trata de autodescubrimiento, como ciudadano con derecho a participar, a tomar decisiones. El descubrimiento de uno mismo nos permite percibir al otro diverso, en una perspectiva de complementariedad.

Palabras clave: Filosofía de la liberación. Decolonialidad. Marxismo.

\section{INTRODUÇÃO}

Com a recente construção de constituições plurinacionais, especialmente com a promulgação das constituições do Equador (2008) e Bolívia (2009), os debates e reflexões sobre decolonialidade ganharam importância no campo do conhecimento jurídico, área que em geral, era bastante refratária a essas ideias. A criação de uma rede para o constitucionalismo democrático na América Latina, a partir de 2011, incentivou o debate e a percepção de uma relação necessária entre o chamado "novo constitucionalismo democrático latino-americano" e os diversos autores que se inserem nos estudos decoloniais. O número de dissertações, teses e artigos científicos sobre o tema é a cada ano maior. A compreensão do poder de superação do Direito moderno liberal europeu pelas constituições plurinacionais, com a apresentação de outras bases epistemológicas, plurais, horizontais e radicalmente democráticas, despertou o interesse dos pensadores de esquerda, incluindo a esquerda marxista. Este debate, que ganha cada vez mais força, gerou reações distintas, desde uma crítica sem reflexão (preconceito) até a tentativa de conciliação entre as duas compreensões de mundo e de ação transformadora da realidade.

Este artigo pretende oferecer uma contribuição a esse debate, trazendo o pensamento de Enrique Dussel, referência nos estudos decoloniais.

A segunda fase da filosofia dussuliana é de uma releitura dos textos de Karl Marx, principalmente assumindo a materialidade. "El objeto a considerar es en primer lugar la producción material (materialle). Individuos que producen en sociedad, o sea producción socialmente determinada de los individuos: éste es naturalmente el punto de partida (Ausgangspunkt)" (Dussel, 1991, p. 38). 
Mas como pensar a realidade da América Latina? É possível a filosofia compreender essa dinâmica latino-americana? É possível ir mais longe e pensar uma filosofia que se adeque a essa realidade? Este trabalho tem como objetivo analisar a iniciativa de Enrique Dussel, que se junta a autores pontuais na tentativa de alteração do cenário filosófico latino-americano e realiza uma reflexão que privilegia a antropologia. Seus pensamentos visam buscar uma nova consciência do que é ser latino-americano e a necessidade de inclusão das reflexões realizadas pelos historicamente excluídos. Esses pontos são fundamentais e basilares para a ética da libertação.

A partir dessa materialidade a reflexão de Dussel passa para a materialidade latinoamericana. É uma virada do "outro", abstrato, para o "pobre", "concreto". "Este ultimo es, manifiestamente, el método científico correcto. Lo concreto es concreto porque es la síntesis de múltiples determinaciones, por lo unidad de lo múltiples. Aparece en el pensar como proceso de sintesis, como resultado, no como punto de partida (...)” (DUSSEL, 1991, p. 48-63)1.

\section{DO POBRE À VÍTIMA}

O outro no olhar de Dussel será o pobre que possui nome, raça, cultura e rosto que está localizado em um continente, país, cidade em um tempo e espaço específicos. Será assim o objeto de reflexão filosófica para propor a Filosofia da Libertação, pois o pobre revela-se como exterioridade radical de uma Totalidade ensimesmada (ALVES, 2005). Entretanto, frente aos acontecimentos políticos e econômicos que trouxeram mudanças globais na década de 90 , Dussel utilizará da categoria vítima para elucidar a pobreza latino-americana ${ }^{2}$, pois a conceituação do outro é limitada.

Um 'absolutamente Outro' seria, nesta Ética, algo como uma tribo amazônica que não tivesse tido nenhum contato com a civilização atual, hoje praticamente inexistente. A liberdade do Outro - seguindo aspecto, a Merleau-Ponty - não pode ser uma incondicionalidade 'absoluta', mas sempre uma quase-incondicionalidade referida ou 'relativa' a um contexto, a um mundo, à facticidade, à factibilidade. Nesta Ética, o Outro não será denominado metaforicamente e economicamente sob o nome de 'pobre'. Agora, inspirando-nos (grifo nosso) em W. Benjamin,

\footnotetext{
${ }^{1}$ A obra Hacia un Marx desconocido: un comentario de los manuscritos del 61-63 (DUSSEL, 1988) será analisado a dependência na América Latina. Enquanto que no livro El ultimo Marx (1863-1882) y la liberación latinoamericana (DUSSEL, 1990) já será abordado o capital latino-americano como questão que irá influenciar da economia a cultura e religião.

${ }^{2}$ Conforme Dussel (1995, p. 11) "os temas que trataremos são de tais dimensões que só tentaremos nesta obra situar 'indicativamente' as questões dentro de uma arquitetura categorial que se desenvolve como um 'processo' ético, a partir da realidade de um processo mundial de globalização excludente".
} 
o denominarei 'a vítima' - noção mais ampla e exata (DUSSEL, 1995, p. 16-17).

A conceituação de 'vítima' assim poderá ser utilizada em diferentes contextos, não apenas América Latina, pois para o autor a "vítima" são todos que de alguma maneira estão excluídos do 'sistema-mundo', o que inclui o próprio planeta em decorrência dos desequilíbrios ecológicos que vem sofrendo em razão de ações humanas (DUSSEL, 1995, p. 19). O pensamento de Dussel caminha para um ethos da humanidade frente às particularidades apresentadas pelos ethos regionais (africano, asiático, indo-afro-latino-americano, europeu), pois o planeta seria assim a face humana mais completa.

Nos dizeres de Dussel (1995, p. 632):

"Desta maneira, uma moral 'universal' (p. ex., a pretensão de Habermas, parágrafo 3.4, mas também, em outro sentido, da ética da libertação) encontra-se num plano diferente do que uma etnicidade 'mundial' (p. ex., o processo futuro de uma cultura mundial, negada na pretensão da modernidade de impor sua particularidade sobre todas as culturas do 'sistema-mundo'), ou de uma ética crítica 'mundial' ou 'planetária' (p. ex., a Ética da Libertação)”.

\section{3 ÉTICA DA LIBERTAÇÃO}

A ética da libertação para Dussel (2000, p. 15) é necessária frente a "miséria que aniquila a maioria da humanidade no final do século XX" e as estratégias de desenvolvimento incompatíveis com ideais de preservação da ecologia do planeta. Será, portanto, uma ética do cotidiano realizada a partir de debates com filósofos, tais como Levinas, Apel, Hinkelammert, Kant, Marx, Habermas, entre outros, que tenham como objetivo a análise do sistema mundo. A ética da libertação, portanto, é uma atitude reflexiva e prática que se manifesta pela da indignação que a desumanização, sentida por grande parte da população, provoca.

A superação da modernidade é essencial, pois Dussel (1994) sustenta, primeiramente, que é preciso à negação de si mesmo. Relembrando que a legitimação da violência foi uma das principais estratégias para a conquista dos povos originários, culpados pelo seu próprio extermínio. Desta forma a negação é da modernidade, reconhecendo-se como inocente. A razão emancipadora da modernidade é superada pela razão libertadora quando é reconhecida a negação da alteridade, que transcende a razão moderna no momento da coexistência com a modernidade (PERDOMO, 2017, p. 107). 
Desse modo, a superação da modernidade só é possível com um projeto de escala global e comprometida com a alteridade negada. Esse projeto Dussel (1994) chama de transmodernidade, onde será possível a inclusão do pensamento binário modernidadealteridade. Para se falar em transmodernidade primeiro é exigido o reconhecimento das culturas que foram excluídas ao longo da história, pois

Lo pos de la postmodernidade no le quita su eurocentrismo, se presupone como obvio que la humanidad futura alcanzará las mismas características como situación cultural que la Europa posmoderna (...). La posmodernidade es profundamente eurocéntrica, ya que no puede imaginar que las culturas excluidas en su positividad valiosa por el proceso moderno colonial (...) pueden contribuir con sus aportes en la construcción de sociedades futuras, posterior a la cultura europea (DUSSEL, 2001, p. 404)

Essa superação é essencial para Dussel, pois somente assim será possível falar em dialogo intercultural, "que não pressupõe a ilusão da simetria inexistente entre as culturas" (DUSSEL, 2016, p. 60). A construção de uma ética da libertação tem seu primeiro passo na 'libertação da cultura popular', que é a libertação do setor social explorados ou oprimidos de uma nação.

"A cultura imperial (supostamente universal) não é a mesmo que a cultura nacional (que não é idêntica à popular), que a cultura ilustrada da elite neocolonial (o que nem sempre é burguesa, mas sim oligárquica), que a cultura de massa (que é alienante e unidimensional, tanto no centro como na periferia), e também não é o mesmo que cultura popular. [E acrescentavámos:] A cultura imperial, ilustrada, e a cultura de massa (onde deve se incluir a cultura proletária como negatividade) são os momentos internos imperantes na totalidade dominante. A cultura nacional é, no entanto, ainda equivocada, embora relevante (...). A cultura popular é a noção chave para a libertação [cultural]" (DUSSEL, 1980, p. 72).

Assim, o conceito de transmoderno significa o surgimento da exterioridade e da alteridade das culturas universais em desenvolvimento que tomam para si o desafio da Modernidade. Seu ponto de partida será de sua experiência cultural, que se difere da euroamericana, para então buscar respostas para uma cultura moderna única. Esta por sua vez será fruto da pluriversalidade rica e de um verdadeiro diálogo intercultural e transversal ${ }^{3}$.

\footnotetext{
${ }^{3}$ Para o autor o diálogo intercultural transversal dá-se a partir da periferia para a periferia, dos movimentos feministas, das lutas antirraciais e anticoloniais. Será o diálogo das diferenças. Mas será também um diálogo com os críticos da própria cultura, definido como intelectuais de fronteira entre a própria cultura e a modernidade (DUSSEL, 2016, p. 63-68).
} 
Distinto ponto objeto de análise será a razão. Para Dussel (2001 e 2000) a razão deve ser constituída de realidade, capaz de compreender a racionalidade como uma capacidade da vida humana que lhe permite criar mecanismos para viver mais e melhor. Sendo a vida o último critério de valor e princípio material. Assim, a ação ética terá como imperativo a produção, reprodução e o desenvolvimento da vida em comunidade ${ }^{4}$. Mas para tanto é preciso criticidade.

É nesse momento que o conceito de vítima se faz presente, pois é a inevitabilidade da existência das vítimas será essencial como discernimento para realizar-se uma análise critica da totalidade de um sistema de eticidade. A partir desse momento o que era apresentado como verdade passa a ser considerado não verdade, o válido como não válido e o bom pode ser considerado mal (DUSSEL, 2000). A razão crítica permitirá o (auto)reconhecimento das vítimas do sistema mundo (dominados: operários, índios, escravos, etc. e os discriminados: mulheres, idosos, incapacitados, imigrantes, etc.), além do descobrimento das alteridades e autonomias negadas. Pois, "a única maneira de levar o oprimido a tomar consciência da opressão que pesa sobre todas as estruturas da sua existência é que descubra, previamente a dialética da dominação concretamente, em todo e em cada momento do seu ser" (DUSSEL, 1977b, p. 191).

Dussel denomina essa razão crítica de Principio da Libertação, onde "a comunidade crítica deve desconstruir efetivamente no sistema sua negatividade e transformá-lo (ou produzir outro novo), para que as vítimas possam viver, participando simetricamente nas decisões.” (DUSSEL, 1995, p. 29). Essas ações, por sua vez, serão chamadas de práxis da libertação:

"Quem reconhece responsavelmente que as vítimas não podem
reproduzir-desenvolver sua vida nem participar simetricamente na
discussão daquilo no qual estão afetadas, está obrigado/a: (a)
negativamente desconstruir realmente as normas, ações, instituições ou
estruturas históricas que originam a negação material da vítima; e (b)
positivamente, transformar ou construir as normas, ações, instituições
ou as estruturas necessárias para que a vítima possa (b.1) viver
humanamente, (b.2) com participação simétrica, (b.3) efetuando
realmente as exigências factíveis ou alternativas que consiste em
transformações, sejam parciais ou estruturais. (DUSSEL, 1986, p. 17).

Comprovando que o a Filosofia da Libertação é um movimento de transformação, pois a partir desse pensamento crítico iniciará um processo que busca "mudar o rumo de uma

\footnotetext{
${ }^{4}$ Ponto que correlaciona-se com a transmodernidade, pois a vida em comunidade pressupõe consenso e este deve ser obtido de forma livre autônoma e racional: "Aceitar o argumento do outro supõe aceitar ao outro como igual, e esta aceitação do outro como igual é uma posição ética, é o reconhecimento ético ao outro como igual, quer dizer, aceitar o argumento não é somente uma questão de verdade é, também, uma aceitação da pessoa do outro. (DUSSEL, 2001c, p. 8).
} 
intenção, o conteúdo de uma norma; modificar uma ação ou instituições possíveis, e até um sistema de eticidade completo, em vista dos critérios e princípios éticos enunciados, no próprio processo estratégico e tático" (DUSSEL, 2000, p. 539) e que tem como consequências diretas a exigência de que as "instituições, o sistema, abram novos horizontes que transcendam a mera reprodução como repetição de 'o mesmo' - e, simultaneamente, expressão e exclusão de vítimas" (DUSSEL, 2000, p. 566)

A transformação virá de um movimento ético-crítico, que terá como característica a dialética, de afirmação-negação, e utilizará do momento analéptico para a revelação do outro enquanto outro. Para Dussel (1986, p. 198) o "discurso negativo a partir da totalidade, porque pensa a impossibilidade de pensar o outro positivamente partindo da própria totalidade; discurso positivo da totalidade, quando pensa a impossibilidade de interpretar a revelação do outro, a partir do outro". A negatividade das vítimas é que possibilita a descoberta a partir da positividade, pois “a condição de possibilidade de conhecer a 'negação' originária sofrida pela vítima consiste numa 'afirmação’ prévia a partir da qual se recorta a negação” (DUSSEL, 2000, p. 374).

Essa conscientização exerce uma ação crítico desconstrutiva e ao mesmo tempo uma ação construtiva, uma vez que levarão às ações de transformações, sejam elas normas, atos, subsistemas, instituições, etc.. São ações que visam a transformação na realidade das vidas das vítimas. Portanto, a Ética da Libertação proposta por Dussel (2000) é uma ética da transformação a começar por ações críticas cotidianas.

A partir desse momento verifica-se a necessidade da solidariedade, muito além do apenas tolerar, pois este apenas afirma direitos subjetivos, mas mantém-se distante da realidade do outro. Essa solidariedade é “dar tempo ao outro no processo de fazer aceitável uma pretensão de validez por meio do consenso teórico, prático e político" (DUSSEL, 2006, p. 3) e para tanto é preciso agir frente ao oponente por uma posição negativa (meio irracional) ou se abnegar de atuar por outros meios que não sejam racionais.

Por solidariedade entendo uma pulsão de alteridade, um desejo metafísico (E. Levinas) pelo outro que se encontra na exterioridade do sistema onde reina a tolerância e a intolerância. É um hacersecargo (isso significa re-spondere: tomar a cargo [spondere] do outro, reflexivamente [re-]) ante o tribunal do sistema que acusa porque se

\footnotetext{
${ }^{5}$ Em síntese Oliveira e Dias (2012) apresentam os cinco estágios no movimento de crítica proposto por Dussel: 1) experiência monológica ou reconhecimento da dor do outro; 2) consciência crítica da negatividade da vida como vítima; 3) consciência crítica sobre o sistema como causa da negatividade da vítima; 4) consciência ético-crítica do sujeito (Outro) negado pelo sistema e 5) compromisso ético-crítico com a transformação da realidade causadora de vítimas.
} 
assume a vítima da injustiça e por isso, aparece denominado como o injusto, o culpado, o réu e refém no sistema em nome do outro. (DUSSEL, 2006b, p. 5).

Trata-se, portanto, de um contradiscurso do eurocentrismo e do pensamento moderno, pois visa à superação da violência da modernidade e a negação do mito civilizatório. A partir da desconstrução desse discurso é possível superar a razão emancipadora (estratégica e instrumental) pela razão libertadora (OLIVEIRA; DIAS, 2012,p. 104).

A reflexão de Dussel se ancora na dialética a fim de pensa-la, repensá-la e conceber uma nova significação para a mesma. Para tanto o autor utiliza-se de Aristóteles, Hegel, Marx e Heidegger para entender que "o âmbito próprio da dialética é o ontológico; isto é, a passagem de um horizonte de entes a outro até seu fundamento" (DUSSEL, 1977b, p. 162). O objetivo de Dussel é romper o modo de compreensão do método dialético para uma percepção da alteridade sem ter que reduzir a totalidade do outro. Esse novo estágio o autor chama de analético.

O método do qual queremos falar, ana-lético, vai mais além, mais acima, vem de um nível mais alto (aná-) que do mero método dialético. O método dialético é o caminho que a totalidade realiza em si mesma: dos entes ao fundamento e do fundamento aos entes. Trata-se agora de um método (ou do domínio explícito das condições de possibilidade) que parte do outro enquanto livre, como um além do sistema de totalidade; que parte, então, de sua palavra, da revelação do outro e que confiado em sua palavra atua, trabalha, serve, cria. O método dia-lético é a expansão dominadora da totalidade de si; a passagem da potência para o ato de "o mesmo". O método analético é a passagem do justo crescimento da totalidade desde o outro e para "servi-lo" criativamente. A passagem da totalidade a um novo momento de si mesma é sempre dia-lética; tinha, porém, razão Feuerbach ao dizer que 'a verdade dialética' (há, pois, uma falsa) parte do diálogo do outro e não do 'pensador solitário consigo mesmo'. A verdadeira dialética tem um ponto de apoio ana-lético (é um movimento ana-dia-lético); enquanto falsa, a dominadora e imortal dialética é simplesmente um motivo conquistador: dialético (DUSSEL, 1986, p. 196-197)

É, portanto, um método radical que terá o outro livre e não oprimido e não violentado em seus direitos; organizado, a partir da diferença. A analética proporcionará um raciocínio critico-reflexivo para que seja realmente um ato de libertação, pois é preciso diálogo. É o exercício consciente e crítico que permite ao sujeito buscar sua emancipação, sair das amarras da dominação e tornar-se um agente ativo e transformador. Esse movimento analético não pode ser apenas a negação da opressão, mas o reconhecimento da exterioridade no rosto do outro de um ser humano autônomo e sujeito de sua história, pois "cada rosto no face-a-face é igualmente a epifania de uma família, de uma classe, de um povo, de uma época da humanidade (...). O 
rosto do outro é uma ana-lógos; ele é já uma 'palavra' primeira e suprema, é o gesto significante essencial (...). A significação antropológica, econômica, política e latino-americana do rosto é a nossa tarefa e nossa originalidade" (DUSSEL, 1977a, p. 201).

"A filosofia latino-americana é o pensar que sabe escutar discipularmente a palavra analética, analógica do oprimido, que sabe comprometer-se com o movimento ou com a mobilização da liberação e, no próprio caminhar, vai passando a palavra reveladora que interpela a justiça; isto é, vai acedendo à interpretação precisa de seu significado futuro. A filosofia, o filósofo, desenvolve ao outro sua própria revelação como renovada e re-criadora, crítica, interpretante. O pensar filosófico não arquiteta a história expressando-a pensativamente para que possa ser arquivada nos museus. O pensar filosófico, como pedagogia analética da libertação latino-americana, é um grito, um clamor, é a exortação do mestre que faz reincidir sobre o discípulo a objeção que antes havia recebido; agora, como revelação duplicadamente provocativa, criadora" (DUSSEL, 1986, p. 211).

Dussel, portanto, propõe a transformação da metafísica ontológica para a metafísica ética, pois não há possibilidade de ser neutro frente a um sistema excludente. Ser neutro é omitir-se perante a injustiça, consequentemente, é uma ação antiética. Assumir uma posição é agir eticamente (ROSA, 2011, p. 140).

\section{4 ÁREA DE ATRITO}

Nesse momento de expansão do pensamento decolonial torna-se muito importante ressaltar os pontos de atrito, desentendimento e mesmo de preconceito, entre o pensamento decolonial, seus teóricos e teorias, e o pensamento construído a partir de Marx, muitos autores importantes de viés marxista, marxiano, neomarxista ou pós-marxista.

Claro que este estudo não cabe nos limites deste artigo, mas vamos buscar uma questão central, um ponto de tensão que tem se manifestado com frequência, e que diria, é muito mais fruto de incompreensão do que qualquer motivação teórica importante. Primeiro, gostaríamos de lembrar o valor imensurável do pensamento de Marx, especialmente quando estudamos os importantes instrumentos que sua obra oferece desde o século XIX, para compreensão e a transformação da economia e sociedades modernas. O pensamento (teoria e filosofia) de Marx é fundamental para a compreensão do sistema mundo moderno, sua organização econômica, social e política e suas transformações históricas em todo o período "moderno". Existem basicamente três maneiras do estudioso lidar com as teorias: a) vestindo os seus instrumentos de compreensão do mundo para entende-lo e transformá-lo (aí a importância de Marx); b) 
dialogando com a teoria para transformá-la e adaptá-la (o que é impossível não fazer pois toda leitura de um texto cientifico/filosófico é sempre o dialogo do leitor e toda a sua percepção de mundo com o que o Autor procurou demonstrar); c) ou, menos importante, ou diria até como uma pretensão impossível, embora muitos insistam em fazê-lo, como o fiel tradutor/interprete das palavras do teórico. Não há dúvida que Marx é um autor moderno e logo, importantíssimo para explicar e decifrar as engrenagens modernas. Não há como superar algo que não se entende. Daí Marx é fundamental. Diria que Marx, ao lado de Freud, traduzem, como ninguém mais foi capaz de fazer, a modernidade e o sujeito moderno. O filósofo Slavoj Zizek, traz em seu pensamento Marx, Hegel, Freud e Lacan, e tem uma interessante e prudente relação com o pensamento decolonial: ele disse para a imprensa brasileira que não conhece, logo, não pode se pronunciar a respeito. Essa seria, para começar, uma importante postura para muitos outros ${ }^{6}$.

A tensão entre os dois campos ocorre principalmente por esse motivo: ainda não se conheceram suficientemente para se gostarem, o que ocorrerá quando baixarem a guarda.

A discussão que mais tem retratado essa tensão, que traduz as diferenças entre a dialética marxista e a analética dusseliana ocorre em torno do conceito de descolonização e decolonialidade. Acredito que é justamente, nesse ponto que pode haver um acordo quando percebemos que são dois conceitos distintos, que tratam de dois momentos distintos da luta contra a opressão do sistema mundo moderno colonial, capitalista e tudo o que vem junto com isso: racismo; homofobia; machismo; miséria; e todas as outras formas de opressão decorrentes da racionalidade moderna. Essa racionalidade moderna é fundada sobre a uniformização; o individualismo; a lógica binária subalterna; o falso universalismo europeu; a crença infundada em uma linearidade histórica e a transformação da natureza em recurso a ser permanentemente explorado.

Retornando a tensão recente, é fácil entender a enorme diferença entre descolonização e decolonialidade. Deixaremos de lado as críticas ao termo "decolonialidade" por ser um anglicismo, por dois motivos: primeiro, o português é a língua do colonizador, do invasor, assim como o inglês, e, segundo, por que a língua (o idioma) deve ser resgatado de seu sequestro pelo estado moderno, e voltar a ser de todos. A língua que falamos nos pertence e podemos ressignificar, mudar, criar, o que já ocorre entre as pessoas em diversas comunidades pelo Brasil. Superada essa questão inicial, e não desmerecendo a importante libertação das línguas do estado e do poder, podemos então enfrentar a clara diferença entre descolonização e decolonialidade.

\footnotetext{
${ }^{6}$ Entrevista disponível em https://www.youtube.com/watch?v=6RZcC9emQQo, acesso em 27 de julho de 2020.
} 
O processo de descolonização, nós séculos XVIII, XIX e XX, significou a derrubada do poder colonial presente nos estados, com suas tropas, instituições, leis e governadores interventores. Assim foi a revolução haitiana; as guerras de independência de vários estados americanos nos séculos XVIII e XIX, e as guerras de libertação nacional, especialmente no pós segunda-guerra mundial na Ásia e África. Entretanto, após muita luta, os territórios libertados se transformam em estados nacionais modernos soberanos. O que isso significa?

Com o tempo, após a independência, os povos perceberam que, embora as tropas coloniais tenham partido, o colonizador deixou um "presente de grego", um "cavalo de tróia". Esses estados mantiveram o sistema econômico do opressor, mantiveram-se organizados na forma de estado nacionais uniformizadores, hierarquizados, e permaneceram falando a língua do invasor. Adotaram, e continuam adotando, até mesmo os nomes e sobrenomes dos invasores, seus valores e religião, seu idioma e seu sistema de "justiça". Seu direito. A esses mecanismos de subalternização que permitem a continuidade da opressão por novos meios, chamamos de decolonialidade. A colonialidade é o que permanece em nosso ser, nas relações poder e na construção do saber. Os colonizados continuaram estudando os autores dos colonizadores, sua filosofia e sua percepção de mundo (colonialidade do saber). Os colonizados continuam a se sentirem subordinados e buscam repetir e copiar o que o colonizador faz (colonialidade do ser). Os colonizados continuam negando a sua diversidade, copiando o estado uniformizador, impondo um idioma oficial, um único sistema jurídico, uma religião e uma burocracia estatal, negando e ocultando a diversidade de valores, de espiritualidades, de línguas e gramáticas, de forma de organização política, social e econômica (colonialidade do poder).

Decoloniadade e marxismo podem e devem dialogar e isso ocorre entre aqueles que entenderam que as duas compreensões falam de mundos diversos que se comunicam, como na representação gráfica presente neste texto. O marxismo fala de dentro da modernidade e procura sua radical transformação. Os pensamentos decoloniais revelam o que está fora da modernidade (a alteridade) e que foi sistematicamente ocultado, destruído e oprimido. O pensamento decolonial revela outras gramáticas, outras "epistemologias"7, outros saberes, outras formas de sentir, perceber e estar no mundo.

É necessário afastar algumas leituras apressadas e logo, equivocadas, que acusam o pensamento decolonial de multicultural. Ora, o multiculturalismo surge no contexto liberal moderno. Não se trata de simplesmente aceitar e reconhecer a existência de diversas culturas inseridas em um sistema único estatal: você pode ter sua cultura desde que se insira e respeite

\footnotetext{
${ }^{7}$ Epistemologia é uma palavra demasiadamente moderna para explicar o que queremos, mas entendam diversidade epistemológica como a diversidade incontável de formas de conhecer, entender, compreender e sentir o mundo.
} 
o sistema econômico e jurídico do estado nacional. Não. Decolonialidade e a ideia da plurinacionalidade no Direito, significam que cada etnia, cada comunidade, pode se organizar segundo sua história e da maneira como a coletividade decidir, dividindo de maneira horizontal, não hierárquica, o espaço territorial do estado plurinacional. Decolonialidade e plurinacionalidade significam dialogo intercultural, democrático e horizontal, possibilitando a construção de um saber/existir transcultural.

\section{CONCLUSÃO}

Conforme dados de 2018 do Banco Mundial, 3,4 bilhões de pessoas ${ }^{8}$ lutam para satisfazer necessidades básicas, isto é, vivem em situação de pobreza e de extrema pobreza. Esse número representa quase metade da população mundial.

Em "Filosofia da Libertação na América Latina", Dussel (1977b) assinala que a interpretação dos entes naturais e a compreensão da natureza serão condicionados ao mundo, desde um mundo histórico, erótico, político ou simbolicamente determinado. Isto é, a natureza é vista desde o centro ou periferia, desde diferentes classes sociais, sistemas políticos e como matéria prima para os meios de produção. Na "Ética da Libertação" (2000) Dussel chama atenção de que vivemos mergulhados no do sistema mundo moderno e sua racionalidade e, consequentemente, não há a superação da contradição capital-trabalho. Será a partir dessas premissas que Dussel irá analisar a natureza e, principalmente, a destruição vida com a miséria que atinge, como visto, quase metade da população mundial.

A relação entre 'homem-natureza' é fundamental para a Revolução Industrial e responsável por vermos nos dias atuais uma sociedade 'agressivo-destrutiva' do ecossistema e que para Dussel (1986b) apresenta a natureza com sua função corrompida, isto é, ela passa a ser instrumento de dominação sobre outros homens, sobre pobres, sobre países periféricos ${ }^{9}$. A sobrevivência passa então a ter um caráter ecológico-político, ou seja, a natureza passa a ter caráter de orientação política (DUSSEL, 2007).

\footnotetext{
8 Dados disponível em: https://www.worldbank.org/pt/news/press-release/2018/10/17/nearly-half-the-worldlives-on-less-than-550-a-day-brazilian-portuguese, acesso em 05 de julho de 2019.

${ }^{9}$ Nos dizeres de Dussel (1986b, p. 212-213), "las transnacionales colocan en los países subdesarrollados las industrias más contaminantes en las menores garantías de seguridad. Los desechos de las fabricas matan los peces y los vegetales de los mares, enrarecen la atmosfera con gases asfixiantes, aniquilan a los productores naturales de oxígeno (...). La respuesta es aumento de contaminación, el colapso ecológico gigantesco crece. Llega el momento en que la naturaleza, como por acto de venganza cósmica, exterminará a la especie do homo de la superficie del planeta Tierra".
} 
Pode-se assim observar que para Dussel (2003) a destruição ecológica juntamente com a miséria, pobreza e opressão são fenômenos sociais provenientes do capitalismo que se opera de forma desigual e dependente. Portanto, é preciso uma reconstrução de uma ética material onde a natureza e pobreza sejam analisados como problemas articulados. Para tanto, é preciso um projeto ecológico libertador com uma integração dos princípios materiais da ética e consensualidade comunitária para a sobrevivência humana. As ideias de Dussel (2007) para o meio ambiente visam à adoção de estratégias políticas para a emancipação dos processos neoliberais hegemônicos. Os princípios políticos libertadores estão diretamente ligados ao campo econômico e político ${ }^{10}$.

A história da América Latina é marcada por uma colonização baseada em relações sociais de exploração, dependência e dominação. Saber da própria história, sem romantismo e pelo olhar do colonizado, é fundamental para refletir o processo social que se deu de forma desigual e opressora no 'novo continente'. É através desse contexto que Dussel propõe a filosofia da libertação com o objetivo principal de analisar a condição humana a partir das classes sociais populares historicamente silenciadas.

O primeiro passo para a filosofia da libertação, trazido pelo autor, é o resgate da identidade cultural latino-americano, pois, a todo povo colonizado é imposta permanentemente sua subalternidade, colocando sempre à frente, a linguagem da nação civilizadora ou cultura metropolitana. Mas para esse importante salto é preciso o despertar como o oprimido, a vítima, o pobre. Esse processo pode ocorrer de várias maneiras e em diferentes estágios da vida.

Escrita inicialmente em um contexto dos anos 70, isto é, em um período de ditadura militar, a filosofia de Dussel está cada dia mais atual mesmo em situações diferentes. Cada vez mais estamos cegos em relação às consequências da modernidade e caímos frequentemente em suas armadilhas. Desse modo, é cada dia mais necessário o despertar como ser latino para conseguir visualizar as consequências das políticas implantadas no país e no mundo, que hoje está em uma virada opressora, porém de modo sutil e até mesmo disfarçada.

A violência contida no período militar ainda é presente na vida dos seres oprimidos e subalternizados. É preciso reconhecer que a violência sempre foi utilizada pelo Estado como método de uniformização da sociedade e exclusão do outro. Esse cenário só modifica-se ao haver reconhecimento da diversidade e singularidades do ser humano.

\footnotetext{
${ }^{10}$ Pois, “até muito recentemente a política não tinha descoberto sua responsabilidade ecológica (...). A previsão de permanência da vida da população de cada nação na humanidade que habita a Terra é primeira e essencial função da política (...). Uma humanidade extinta obviamente aniquilaria o campo político e todos seus sistemas possíveis" (DUSSEL, 2007, p. 64).
} 
A libertação da colonialidade não começou como um projeto filosófico, é a história luta e da resistência na América indo-afro-latina, mas hoje se coloca como uma filosofia de alcance mundial.

A filosofia da libertação proporciona o autodescobrimento, como um ser cidadão com direito de participação, de escolhas. A descoberta de si mesmo permite perceber o outro diverso, dentro de uma perspectiva de complementaridade. O colonizador que impunha o se ser como modelo a ser (mal) copiado, passa a ser visto em sua exterioridade. Não mais como modelo de nada, mas como mais um, sem sua singularidade. Esse olhar deve ser através da alteridade, sem preconceitos. Um ser liberto e com a capacidade de perceber a diversidade de olhares, de percepções e sentidos, está apto a construir uma outra realidade, plural, democrática, diversa, complementar e justa. Somente um ser liberto terá voz e força para seguir em busca de um mundo que clama por ser harmônico, pacífico e bom.

\section{REFERÊNCIAS}

\section{Livros}

DUSSEL, Enrique. 20 teses de política. São Paulo: Expressão Popular, 2007.

DUSSEL, Enrique. El ultimo Marx (1863-1882) y la liberación latinoamericana. México: Siglo XXI, 1990.

DUSSEL, Enrique. Ética da libertação na idade da globalização e da exclusão. Petrópolis: Vozes, 2000.

DUSSEL, Enrique. Para una ética de la liberación latinoamericana. Tomo III. Buenos Aires: Siglo XXI Argentina Editores, 1977a.

DUSSEL, Enrique. Filosofia da libertação na América Latina. São Paulo: Loyola, 1977b.

DUSSEL, Enrique. Filosofia da libertação: crítica à ideologia da exclusão. São Paulo: Editora Paulus, 1995.

DUSSEL, Enrique. Hacia un Marx desconocido: un comentario de los manuscritos del 6163. Iztapalapa: Siglo XXI, 1988.

DUSSEL, Enrique. Hacia una filosofía política crítica. Espanha: Descleé de Broouwer, 2001. DUSSEL, Enrique. La pedagogica latinoamericana. Bogotá: Editorial Nueva America. 1980 DUSSEL, Enrique. La producción teórica de Marx: un comentario a los Grundrisse. Buenos Aires: Siglo XXI Argentina Editores, 1991. 
DUSSEL, Enrique. Método para uma filosofia da libertação. São Paulo: Editora Loyola, 1986.

DUSSEL, Enrique. 1492 - El encubrimiento del otro: hacia el origen del "mito de la modernidad". La Paz: Plural editores, 1994.

\section{Artigos}

ALVES, Claudenir Módolo. Ética da Libertação: a vítima na perspectiva dusseliana. Dissertação de mestrado apresentado Pontifícia Universidade Católica de São Paulo. São Paulo: 2005.

CALVANCATE, José. A perspectiva filosófica de Enrique Dussel. In: Revista Sophia: colección de filosofía de la educación. № 12, 2012, p. 207-218.

DUSSEL, Enrique. Alguns princípios para uma ética material da libertação. In: PIXLEY, Jorge (coord). Por um mundo diferente: alternativas para o mercado global. Petrópolis: Editora Vozes, 2003, p. 23-35.

DUSSEL, Enrique. Ética ecológico-cultural. In: DUSSEL, Enrique. Ética comunitária. São Paulo: Paulinas, 1986b, p. 209-220.

DUSSEL, Enrique. Europa, modernidade e eurocentrismo. In: LANDER, Edgardo (org). A colonialidade do saber: eurocentrismo e ciências sociais: perspectivas latino-americanas. Buenos Aires: CLASCO, 2005, p. 55-70.

DUSSEL, Enrique. Transmodernidade e interculturalidade: interpretação desde a Filosofia da libertação. In: Revista Sociedade e Estado, vol. 31, nº 1, 2016, p. 51-73.

DUSSEL, Enrique. Seminário de ética. México: Unam, $2001 \mathrm{~b}$.

DUSSEL, Enrique. Seminário de ética. México: Unam, 2001c.

OLIVEIRA, Ivanilde Apoliceno; DIAS, Alder Sousa. Ética da Libertação de Enrique Dussel: caminho de superação do irracionalismo moderno e da exclusão social. In: Conjectura, vol. 17, no 3, 2012, p. 90-106.

PERDOMO, Diego Fernando Camelo. Enrique Dussel y el mito de la modernidad. In: Cuadernos de Filosofía Latinoamericana, vol. 38, n 116, 2017, p. 97-115.

ROSA, Luís Carlos Dalla. A alteridade e a relação pedagógica no pensamento de Enrique Dussel. In: Revista Diálogo, no 19, 2011, p. 131-144. 
